\title{
Analysis of the Interaction between Polygenic Risk Score and Calorie Intake in Obesity in the Korean Population
}

\author{
Won-Jun Lee ${ }^{a}$ Ji Eun Lim ${ }^{b}$ Hae Un Jung ${ }^{a}$ Ji-One Kang ${ }^{b}$ Taesung Park ${ }^{c} d$ \\ Sungho Won ${ }^{\text {e }}$ Sang Youl Rhee ${ }^{f}$ Mi Kyung Kim ${ }^{\text {g, h }}$ Yeon-Jung Kim ${ }^{\mathrm{i}}$ \\ Bermseok Ohb \\ ${ }^{a}$ Department of Biomedical Science, Graduate School, Kyung Hee University, Seoul, South Korea; ${ }^{b}$ Department \\ of Biochemistry and Molecular Biology, School of Medicine, Kyung Hee University, Seoul, South Korea; \\ 'Interdisciplinary Program in Bioinformatics, Seoul National University, Seoul, South Korea; ${ }^{d}$ Department of \\ Statistics, Seoul National University, Seoul, South Korea; ${ }^{e}$ Department of Public Health Science, Seoul National \\ University, Seoul, South Korea; ${ }^{\mathrm{f} D e p a r t m e n t}$ of Endocrinology and Metabolism, School of Medicine, Kyung Hee \\ University, Seoul, South Korea; ${ }^{9}$ Department of Preventive Medicine, College of Medicine, Hanyang University, \\ Seoul, South Korea; ${ }^{\mathrm{h}}$ Institute for Health and Society, Hanyang University, Seoul, South Korea; \\ 'Division of Biobank for Health Science, Center for Genome Science, Korea National Institute of Health, \\ Chungcheongbuk-do, South Korea
}

\section{Keywords}

Polygenic risk score $\cdot$ Calorie intake $\cdot$ Interaction · Obesity ·

Body mass index

\begin{abstract}
Introduction: Obesity results from an imbalance in the intake and expenditure of calories that leads to lifestyle-related diseases. Although genome-wide association studies (GWAS) have revealed many obesity-related genetic factors, the interactions of these factors and calorie intake remain unknown. This study aimed to investigate interactions between calorie intake and the polygenic risk score (PRS) of BMI. Methods: Three cohorts, i.e., from the Korea Association REsource (KARE; $n=8,736$ ), CArdioVAscular Disease Association Study (CAVAS; $n=9,334$ ), and Health EXAminee (HEXA; $n=28,445$ ), were used for this study. BMI-related genetic loci were selected from previous GWAS. Two scores, PRS, and association (a)PRS, were used; the former was determined from 193 single-nucleotide polymorphisms (SNPs) from 5
\end{abstract}

karger@karger.com www.karger.com/lfg

Karger ${ }^{\prime \prime} \div$

BOPEN ACCESS
(C) 2020 The Author(s)

Published by S. Karger AG, Basel

This article is licensed under the Creative Commons AttributionNonCommercial-NoDerivatives 4.0 International License (CC BY NC-ND) (http://www.karger.com/Services/OpenAccessLicense) Usage and distribution for commercial purposes as well as any distribution of modified material requires written permission.
GWAS datasets, and the latter from 62 SNPs (potentially associated) from 3 Korean cohorts (meta-analysis, $p<0.01$ ). $\boldsymbol{R e}$ sults: PRS and aPRS were significantly associated with BMI in all 3 cohorts but did not exhibit a significant interaction with total calorie intake. Similar results were obtained for obesity. PRS and aPRS were significantly associated with obesity but did not show a significant interaction with total calorie intake. We further analyzed the interaction with protein, fat, and carbohydrate intake. The results were similar to those for total calorie intake, with PRS and aPRS found to not be associated with the interaction of any of the 3 nutrition components for either BMI or obesity. Discussion: The interaction of BMI PRS with calorie intake was investigated in 3 independent Korean cohorts (total $n=35,094$ ) and no interactions were found between PRS and calorie intake for obesity.

(c) 2020 The Author(s)

Published by S. Karger AG, Basel

W.-J.L. and J.E.L. contributed equally to this work.
Bermseok Oh

Department of Biochemistry and Molecular Biology

Kyung Hee University, 26 Kyungheedae-ro

Dongdaemun-gu, Seoul 130-701 (South Korea)

ohbs@khu.ac.kr 


\section{Introduction}

Obesity is a major risk factor for lifestyle-related diseases, such as type 2 diabetes, hyperlipidemia, and hypertension, and its prevalence has steadily increased in the past few decades [1]. Overweight individuals have a reduced capacity to cope with emergency situations and are more susceptible to joint diseases [2]. Furthermore, the most prominent cause of sleep apnea is obesity, and obese individuals are frequently diagnosed with various mental illnesses, such as attention deficit hyperactivity disorder and Asperger syndrome [3].

Individuals consuming excess calories are highly susceptible to obesity if they do not also ingest enough nutrients [4-7]. A lack of exercise and unstable lifestyle can induce obesity [8]. Stress, in particular, is one of the most prominent causes of obesity and is often caused by a lack of sleep and can lead to eating disorders or a decreased metabolic rate [9-11]. Although the environmental risk factors for obesity have been characterized, the associated genetic etiologies are only gradually being defined via genome-wide association studies (GWAS) [12-15].

Since the discovery of the FTO and MC4R variants [16, 17], serial GWAS have focused on individuals with obesity [12-15]. One such study comprised approximately 700,000 individuals including 450,000 UK Biobank participants, and reported a total of 536 loci, accounting for approximately $6 \%$ of BMI variations [15]. Although most GWAS on obesity have involved European populations, several have also included Asian populations [18, 19]. Specifically, Akiyama et al. [19] identified 112 new BMIrelated genetic loci using 173,430 Japanese participants.

Among the obesity loci identified by various GWAS, genetic variants of FTO and MC4R have been assessed for their interactions with environmental factors and suggest that multiple environmental factors affect the effect size of these genetic variants [20-23]. These results imply that the carriers of alleles associated with a risk of obesity may be less affected by their genetic factors if environmental factors like diet and physical activity are modified. The polygenic risk score (PRS), determined from a GWAS dataset of single-nucleotide polymorphisms (SNPs) often serves as an index for the genetic susceptibility of individuals to a disease, and the identification of environmental factors interacting with the PRS can, potentially, help individuals with a high genetic risk [24-26].

Numerous studies have reported the interaction between PRS and environmental factors in obesity. The obesity PRS reportedly interacts with sedentary behavior such as watching television [27], the consumption of

Interaction Analyses of PRS and Calorie Intake in BMI and Obesity high-sugar-containing beverages [28], and fried food [29]. Several lifestyle-related factors, including nutrient and alcohol intake and exercise, were reported for their interaction in Japanese individuals [30]. Recently, Tyrrell et al. [31] assessed 12 obesogenic environments to determine their interactions with the PRS composed of 69 BMI-related GWAS loci in the UK Biobank, involving 120,000 participants, and reported PRS-environment interactions with Townsend deprivation index, watching television, and physical activity. However, no study has yet assessed the interaction between BMI PRS and total calorie intake [31].

In this study, the interactions of PRS and association PRS (aPRS) with calorie intake, including total calorie intake and protein, fat, and carbohydrate intake, in BMI and obesity, were investigated in the Korean population.

\section{Materials and Methods}

\section{Study Participants}

We used 3 Korean cohorts for identifying the association and interaction of BMI and obesity: the Korea Association REsource (KARE; $n=8,444$ ), the CArdioVAscular Disease Association Study (CAVAS; $n=9,300$ ), and the Health EXAminee (HEXA; $n=17,350)$ cohorts. All 3 cohorts are currently being assessed as part of the Korean Genome and Epidemiology Study (KoGES) [32]. The KARE was initiated in 2001 and contains epidemiological and genetic data from 10,038 participants aged 40-69 years, 8,840 of whom were included in this study after a sample quality control assessment in accordance with the following exclusion criteria: history of cancer, sex inconsistencies, cryptic relatedness, low genotype call rate $(<95 \%)$, and sample contamination. For BMI analysis, 8,444 subjects with complete data on BMI and total calorie, protein, fat, and carbohydrate intake were included. For obesity case-control analysis, subjects were divided into 2 groups based on their BMI. The obese group $(n=3,632)$ with a BMI $\geq 25$ and the normal group $(n=4,812)$ with a BMI $<25$ [33]. The study design is summarized in Figure 1.

The CAVAS population-based cohort comprises 28,338 subjects aged 40-69 years. We selected 11,100 who were recruited from Yangpyeong, Namwon, and Goryeong in South Korea from 2005 to 2011 [34]. The quality control criteria were the same as for the KARE cohort. For the BMI analysis, 9,300 subjects were assessed, including 3,764 obese and 5,536 normal subjects for the obesity case-control analysis.

The HEXA population-based cohort comprises 173,357 subjects aged 40-79 years, 28,445 of whom were included in this study according to the same inclusion criteria as for the KARE cohort. For the BMI analysis, 17,350 subjects were assessed, including 5,170 obese and 12,180 normal subjects for the obesity case-control analysis.

\section{Genotyping Analysis}

Genotyping analysis for the KARE cohort was performed using a genome-wide human SNP array 5.0 (Affymetrix, Santa Clara, 


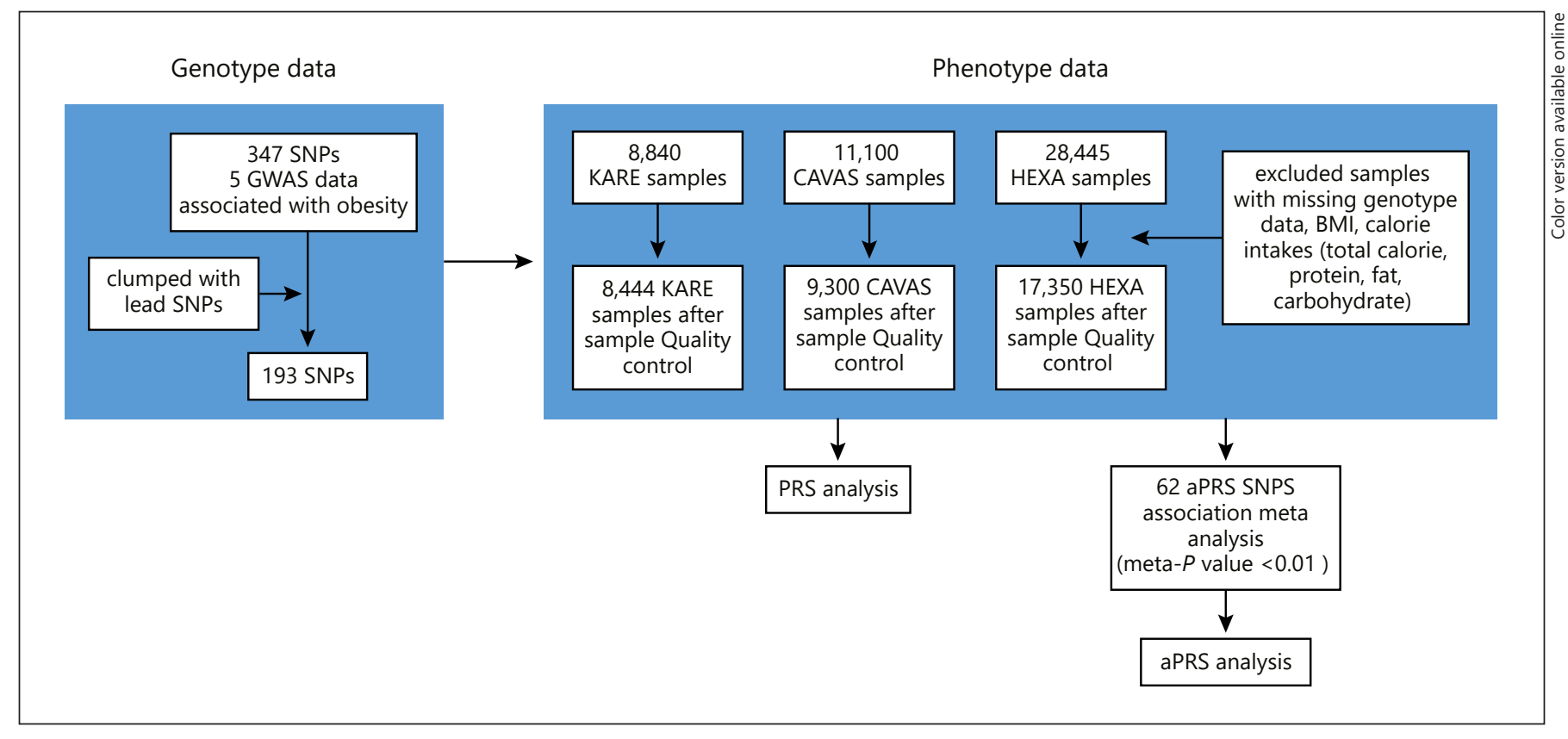

Fig. 1. Schematic diagram of the study design. Summary of data included in this study. A total of 193 genetic variants selected from 5 GWAS publications were used in the PRS analysis and 62 variants potentially associated in 3 Korean cohorts were used in the aPRS analysis, resulting in 35,094 Korean samples $(8,444$ from KARE, 9,300 from CAVAS, and 17,350 from HEXA) being included in the PRS and aPRS analyses.

CA, USA), as previously described [32], and SNP imputation was performed with IMPUTE2 [35] using phase 1 of the 1000 Genomes Project as a reference panel. Genetic variants with a high missing call rate $(>5 \%)$, a low minor allele frequency (MAF $<0.05)$, a Hardy-Weinberg equilibrium (HWE) of $p \leq 1 \times 10^{-6}$, and a low imputation quality (info score $<0.4$ ) were excluded.

The CAVAS and HEXA population were genotyped using the Korea Biobank array (KoreanChip), designed by the Center for Genome Science, Korea National Institute of Health (KNIH), based on the platform of UK Biobank axiom array and manufactured by Affymetrix [36]. The SNP imputation method and genotype quality control criteria were the same as for KARE.

\section{Selection of BMI-Associated SNPs and Determination of the $P R S$ and $a P R S$}

In total, 347 BMI-related SNPs were identified from 5 BMIrelated GWAS that included analyses of Asian populations [13, 14, $18,19,32]$. Independent SNPs were identified using clumping analysis in PLINK v1.9, with the following set parameters: $p$ value $\left(<5 \times 10^{-8}\right)$, genomic distance $(<1 \mathrm{Mb})$, and linkage disequilibrium $\left(r^{2}>0.2\right)$. Thereafter, we selected only 1 top-ranked SNP with the lowest $p$ value from each clump within a $1-\mathrm{Mb}$ range based on GWAS data. We then obtained a total of 193 independent SNPs and verified whether they were included in the imputed genotype data of each cohort. Consequently, 193 SNPs were selected for the PRS in KARE, 152 in CAVAS, and 192 in HEXA. We calculated each individual PRS using the selected SNPs, by summing risk alleles with weighting the effect size of each allele or without weighting $\left(\mathrm{PRS}_{\text {unweighted }}\right)$ [31]. The unweighted PRS were calculated by summing the number of risk alleles without applying the weight of effect size ( unweighted $P R S=S N P_{1}+S N P_{2}+\ldots+S N P_{n}$ ). Meanwhile, the weighted PRS were calculated according to Equation 1, by creating a weighted score by summing the number of risk allele multiplied by the effect size (weighted score $=\beta_{1} \times S N P_{1}+\beta_{2} \times S N P_{2}$ $\left.+\ldots+\beta_{n} \times S N P_{n}\right)$, followed by rescaling the weighted score to represent the number of risk alleles [31].

$$
\text { weighted PRS }=\frac{\text { weighted score } \times \text { number of available SNPs }}{\text { sum of the } \beta \text { coefficients of available SNPS }}
$$

To determine the aPRS, we carried out association meta-analyses of BMI using the 3 cohorts, and selected SNPs that were BMIassociated (meta-analysis, $p<0.01$; online suppl. Table S1; see www.karger.com/doi/10.1159/000511333 for all online suppl. material). Consequently, 62 SNPs were selected for the aPRS in each cohort. We calculated each individual aPRS using the selected SNPs, by summing risk alleles with weighting the effect size of each allele or without weighting ( $\left.\mathrm{aPRS}_{\text {unweighted }}\right)$. The average PRS and aPRS in each cohort are shown in online supplementary Table S2.

We also created an additional PRS ${ }^{2}$ using a total of 941 independent SNPs more recently identified in a BMI GWAS of approximately 700,000 individuals with European ancestry [15]. After selection of SNPs for the imputed genotype data of each cohort, 768 were selected for the PRS ${ }^{2}$ in KARE, 634 in CAVAS, and 823 in HEXA (online suppl. Table S3). We then calculated each individual PRS ${ }^{2}$ using the SNPs, by summing risk alleles either with weighting of the effect size of each allele or without weighting $\left(\mathrm{PRS}^{2}\right.$ unweighted) [31]. Similarly, for $\mathrm{PRS}^{2}$, we carried out association meta-analyses of BMI using the 3 cohorts, and selected SNPs that were BMI-associated (meta-analysis, $p<0.01$ ). Consequently, 61 
Table 1. Baseline characteristics of the 3 Korean cohorts

\begin{tabular}{lccc}
\hline Characteristics & KARE & CAVAS & HEXA \\
\hline Subjects, $n$ & 8,444 & 9,300 & 17,350 \\
Males, $n(\%)$ & $4,044(47.90)$ & $3,455(37.15)$ & $5,976(34.44)$ \\
Age, years & $52.16(8.90)$ & $62.16(9.72)$ & $53.81(7.89)$ \\
BMI & $24.60(3.13)$ & $24.38(3.17)$ & $23.81(2.67)$ \\
Obesity, $n(\%)$ & $4,312(43.01)$ & $3,764(40.47)$ & $5,170(29.80)$ \\
Calorie intake, kcal & $1,918.896(681.336)$ & $1,559.352(493.118)$ & $1,759.130(537.348)$ \\
Protein intake, g & $66.664(30.043)$ & $46.704(19.990)$ & $59.673(24.990)$ \\
Fat intake, g & $32.574(21.120)$ & $19.050(14.102)$ & $27.818(17.116)$ \\
Carbohydrate intake, g & $344.182(118.714)$ & $294.330(84.956)$ & $313.479(88.348)$ \\
\hline
\end{tabular}

Data are presented as mean (SD), unless otherwise indicated.

SNPs were selected for the aPRS ${ }^{2}$ in each cohort (online suppl. Table S3). Individual aPRS ${ }^{2}$ were calculated in the same way as that described for $\mathrm{PRS}^{2}$. The average $\mathrm{PRS}^{2}$ and $\mathrm{APRS}^{2}$ in each cohort are shown in online supplementary Table S3.

\section{Measurements}

Weight and height were measured via standard procedures. For each cohort, BMI was calculated as weight divided by height squared. For the association analysis of obesity, subjects were dichotomized into a normal $(\mathrm{BMI}<25)$ and an obese $(\mathrm{BMI} \geq 25)$ group [33].

A previously validated $[37,38]$ food frequency questionnaire was used to obtain the total calorie, protein, carbohydrate, and fat intake. The fat intake value did not include the amount of oil used in cooking [38].

\section{Statistical Analysis}

Linear regression analysis was performed for the association between calorie intake and BMI, and logistic regression analysis was performed for obesity cases and control tests using SPSS (PASW Statistics v23.0). All regression analyses were adjusted for age, sex, recruitment site, and 10 principal components for the KARE cohort, and for age, sex, and 10 principal components for the CAVAS and HEXA cohorts. The 10 principal components were calculated using the -pca option in PLINK v1.90 to account for population stratification.

Associations between genetic factors (individual SNPs, PRS, and aPRS) and obesity were assessed by a linear regression analysis for BMI; a logistic regression analysis was used for obesity. For each analysis, age, sex, recruitment site, and 10 principal components were adjusted for the KARE cohort, and age, sex, and 10 principal components for the CAVAS and HEXA cohorts. We used PLINK v1.90 to conduct individual SNP association analysis to select SNPs for aPRS and calculate PRS and aPRS [39]. In addition, we used SPSS v25 for the association and interaction analyses of PRS and aPRS for each cohort. All data were reported as mean \pm SD. $p<4.17 \times 10^{-4}(0.05 / 120)$ was considered statistically significant after multiple-correction analysis considering 4 scoring indices (PRS, PRS unweighted, $_{\text {aPRS, and aPRS }}$ unweighted $), 5$ analyses ( 1 association analysis and 4 interaction analyses with lifestyle factors), 2 outcomes (BMI and obesity), and 3 Korean cohorts.

Interaction Analyses of PRS and Calorie Intake in BMI and Obesity

\section{Results}

Association of Calorie Intake with BMI and Obesity

The characteristics of each cohort appear in Table 1 and online supplementary Table S4. For BMI analysis (Table 1), 8,444 participants $(4,044$ men) were selected from the KARE cohort, 9,300 (3,455 men) from the CAVAS cohort, and 17,350 (5,976 men) from the HEXA cohort. The mean BMI was $24.60 \pm 3.13$ in KARE, $24.38 \pm$ 3.17 in CAVAS, and $23.81 \pm 2.67$ in HEXA. The average total calorie intake, protein intake, fat intake, and carbohydrate intake values are shown in Table 1.

Total calorie intake (per 1-SD) was significantly associated with BMI in all 3 cohorts: $\beta \pm \mathrm{SE}=0.162 \pm 0.34$, $p=2.00 \times 10^{-6}$ in KARE; $\beta \pm \mathrm{SE}=0.249 \pm 0.035, p=6.84 \times$ $10^{-13}$ in CAVAS; and $\beta \pm \mathrm{SE}=0.103 \pm 0.020, p=4.14 \times$ $10^{-7}$ in HEXA. Protein intake (per 1-SD) was also significantly associated with $\mathrm{BMI}$ in all 3 cohorts: $\beta \pm \mathrm{SE}=0.151$ \pm 0.034 in KARE; $\beta \pm \mathrm{SE}=0.217 \pm 0.035$ in CAVAS; and $\beta \pm \mathrm{SE}=0.101 \pm 0.020$ in HEXA. Fat intake (per 1-SD) was significantly associated with BMI in HEXA, but not in KARE or CAVAS following multiple corrections considering the 4 lifestyle factors, 2 outcomes (BMI and obesity), and 3 Korean cohorts $\left(p<2.08 \times 10^{-3}\right)$. Carbohydrate intake (per 1-SD) was significantly associated with BMI in all 3 cohorts: $\beta \pm \mathrm{SE}=0.175 \pm 0.034$ in KARE; $\beta \pm$ $\mathrm{SE}=0.257 \pm 0.034$ in CAVAS; and $\beta \pm \mathrm{SE}=0.093 \pm 0.020$ in HEXA. The associations of calorie and macronutrient intake with BMI are shown in Table 2.

Online supplementary Table S4 shows the basic characteristics of obesity cases and controls in each cohort. The KARE cohort comprised 3,632 cases (BMI $\geq 25$, mean BMI $27.43 \pm 2.09)$ and 4,812 controls (BMI $<25$, mean BMI $22.47 \pm 1.82$ ). The CAVAS cohort comprised 3,764 
cases (mean BMI $27.4 \pm 2.07$ ) and 5,536 controls (mean BMI $22.32 \pm 1.88$ ). The HEXA cohort comprised 5,170 cases (mean BMI 26.96 \pm 1.83 ) and 12,180 controls (mean BMI $22.48 \pm 1.66)$.

Total calorie intake (per 1-SD) was significantly associated with obesity in all 3 cohorts: odds ratio (OR) 1.086 (95\% confidence interval [CI] 1.040-1.135), $p=2.24 \times$ $10^{-4}$ in KARE; OR 1.148 (95\% CI 1.098-1.201), $p=1.51$ $\times 10^{-9}$ in CAVAS; and OR 1.074 (95\% CI 1.039-1.111), $p=2.30 \times 10^{-5}$ in HEXA (online suppl. Table S5). Protein intake (per 1-SD) was also significantly associated with obesity in all 3 cohorts: OR 1.087 (95\% CI 1.040-1.136) in KARE; OR 1.137 (95\% CI 1.087-1.190) in CAVAS; and OR 1.072 (95\% CI 1.037-1.107) in HEXA. Fat intake (per $1-\mathrm{SD})$ was not significant in any of the 3 cohorts after multiple correction $\left(p<2.08 \times 10^{-3}\right)$. Carbohydrate intake (per 1-SD) was significantly associated with obesity in all 3 cohorts: OR 1.089 (95\% CI 1.042-1.137) in KARE; OR 1.148 (95\% CI 1.099-1.200) in CAVAS; and OR 1.067 (95\% CI 1.032-1.103) in HEXA.

\section{Association of PRS and aPRS with BMI and Obesity}

We determined the PRS on the basis of BMI-related GWAS SNPs by accounting for the effect weight of each SNP in the PRS computation. Starting from 347 GWAS SNPS, we used 193 SNPs for KARE, 152 for CAVAS, and 192 for HEXA, depending on the imputed genotype data of each cohort (online suppl. Table S2). Association analysis of the PRS was performed using linear regression for $\mathrm{BMI}$ and logistic regression for obesity. As shown in Table 3 , the PRS was significantly associated with BMI $(\beta \pm$ $\mathrm{SE}=0.015 \pm 0.002, p=3.96 \times 10^{-22}$ in KARE; $\beta \pm \mathrm{SE}=$ $0.012 \pm 0.002, p=8.23 \times 10^{-12}$ in CAVAS; and $\beta \pm \mathrm{SE}=$ $0.013 \pm 0.001, p=6.73 \times 10^{-38}$ in HEXA). The associations of PRS with BMI in the 3 cohorts appear as scatter plots in online supplementary Figure S1. Online supplementary Table S6 shows that PRS was significantly associated with obesity (OR 1.008 [95\% CI 1.006-1.010], $p=4.71 \times$ $10^{-14}$ in KARE; OR 1.006 [95\% CI 1.004-1.009], $p=$ $4.99 \times 10^{-8}$ in CAVAS; and OR 1.008 [95\% CI 1.007$1.010], p=1.15 \times 10^{-22}$ in HEXA).

We determined the unweighted PRS ( $\mathrm{PRS}_{\text {unweighted }}$ ) using the same SNPs as those for PRS, without accounting

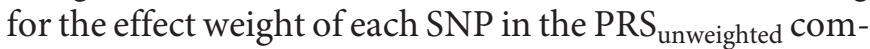
putation. Association analysis of the $\mathrm{PRS}_{\text {unweighted was }}$ performed and was also determined to be significantly associated with BMI and obesity in all 3 cohorts (Table 3; online suppl. Table S6).

In addition, we determined the aPRS on the basis of 62 BMI-related SNPs validated by the meta-analysis of the 3
Table 2. Association analyses of calorie and macronutrient intake with BMI

\begin{tabular}{llll}
\hline Study & $\begin{array}{l}\text { Environmental effect } \\
\text { (intake) }\end{array}$ & BMI & \\
\cline { 3 - 4 } & & $\beta(\mathrm{SE})$ & $p$ value \\
\hline KARE & Total calories (1-SD) & $0.162(0.034)$ & $\mathbf{2 . 0 0 E - 0 6}$ \\
& Protein (1-SD) & $0.151(0.034)$ & $\mathbf{1 . 1 0 E - 0 5}$ \\
& Fat (1-SD) & $0.072(0.035)$ & $4.05 \mathrm{E}-02$ \\
& Carbohydrates (1-SD) & $0.175(0.034)$ & $\mathbf{3 . 4 5 E}-07$ \\
\hline CAVAS & Total calories (1-SD) & $0.249(0.035)$ & $\mathbf{6 . 8 4 E - 1 3}$ \\
& Protein (1-SD) & $0.217(0.035)$ & $\mathbf{5 . 3 6 E - 1 0}$ \\
& Fat (1-SD) & $0.089(0.035)$ & $1.14 \mathrm{E}-02$ \\
& Carbohydrates (1-SD) & $0.257(0.034)$ & $\mathbf{2 . 3 5 E - 1 4}$ \\
\hline HEXA & Total calories (1-SD) & $0.103(0.020)$ & $\mathbf{4 . 1 4 E - 0 7}$ \\
& Protein (1-SD) & $0.101(0.020)$ & $\mathbf{5 . 2 9 E}-07$ \\
& Fat (1-SD) & $0.067(0.020)$ & $\mathbf{1 . 0 5 E - 0 3}$ \\
& Carbohydrates (1-SD) & $0.093(0.020)$ & $\mathbf{4 . 0 0 E - 0 6}$ \\
\hline
\end{tabular}

The associations of calorie and macronutrient intakes (per 1-SD) with BMI were analyzed by linear regression model, adjusted for age, sex, and recruitment area in KARE, and for age and sex in CAVAS and HEXA. The significance threshold was $p<2.08 \mathrm{E}-03$ (0.05/24 after multiple correction). SE, standard error; BMI, body mass index.

cohorts $(p<0.01)$. Similar to the PRS, the aPRS was calculated by accounting for the effect weight of each SNP. Association analysis of the aPRS was performed using linear regression for BMI and logistic regression for obesity. The aPRS was found to be significantly associated with $\mathrm{BMI}\left(\beta \pm \mathrm{SE}=0.020 \pm 0.003, p=1.46 \times 10^{-12}\right.$ in KARE; $\beta \pm \mathrm{SE}=0.019 \pm 0.003, p=2.00 \times 10^{-12}$ in CAVAS; and $\beta \pm \mathrm{SE}=0.019 \pm 0.002, p=8.15 \times 10^{-29}$ in HEXA; Table 4) and obesity (OR 1.010 [95\% CI 1.007-1.014], $p=$ $3.60 \times 10^{-8}$ in KARE; OR 1.010 [95\% CI 1.007-1.014], $p=1.59 \times 10^{-8}$ in CAVAS; and OR 1.012 [95\% CI 1.009$1.015], p=2.14 \times 10^{-17}$ in HEXA; online suppl. Table S7).

We also determined the aPRS unweighted $_{\text {using the same }}$ 62 SNPs, without accounting for the effect weight of each SNP. Association analysis of the aPRS $\mathrm{unweighted}_{\text {was also }}$ significantly associated with $\mathrm{BMI}(\beta \pm \mathrm{SE}=0.076 \pm 0.007$, $p=2.34 \times 10^{-29}$ in KARE; $\beta \pm \mathrm{SE}=0.069 \pm 0.006, p=$ $8.07 \times 10^{-27}$ in CAVAS; and $\beta \pm \mathrm{SE}=0.063 \pm 0.004, p=$ $5.62 \times 10^{-56}$ in HEXA; Table 4$)$ and obesity (OR 1.041 [95\% CI 1.032-1.050], $p=4.15 \times 10^{-19}$ in KARE; OR 1.040 [95\% CI 1.031-1.049], $p=9.67 \times 10^{-20}$ in CAVAS; and OR 1.056 [95\% CI 1.044-1.069], $p=1.70 \times 10^{-20}$ in HEXA; online suppl. Table S7).
Lee/Lim/Jung/Kang/Park/Won/Rhee/ $\mathrm{Kim} / \mathrm{Kim} / \mathrm{Oh}$ 
Table 3. Association and interaction analyses of PRS with BMI

\begin{tabular}{|c|c|c|c|c|}
\hline \multirow[t]{2}{*}{ Study } & & \multirow[t]{2}{*}{ Test } & \multicolumn{2}{|l|}{ BMI } \\
\hline & & & $\beta(\mathrm{SE})$ & $p$ value \\
\hline \multirow[t]{12}{*}{ KARE } & PRS & Genetic effect (G) & $1.58 \mathrm{E}-02(1.63 \mathrm{E}-03)$ & $3.96 \mathrm{E}-22$ \\
\hline & & Interaction effect (GxE) & & \\
\hline & & Calorie intake (1-SD) & $-1.65 \mathrm{E}-03$ (1.65E-03) & 0.319 \\
\hline & & Protein $(1-S D)$ & $1.10 \mathrm{E}-04(1.68 \mathrm{E}-03)$ & 0.948 \\
\hline & & Fat (1-SD) & $4.73 \mathrm{E}-04(1.60 \mathrm{E}-03)$ & 0.768 \\
\hline & & Carbohydrate (1-SD) & $-2.44 \mathrm{E}-03(1.66 \mathrm{E}-03)$ & 0.141 \\
\hline & PRS $_{\text {unweighted }}$ & Genetic effect $(G)$ & 4.90E-02 (3.79E-03) & $8.37 \mathrm{E}-38$ \\
\hline & & Interaction effect (GxE) & & \\
\hline & & Calorie intake (1-SD) & $-2.43 \mathrm{E}-03(3.74 \mathrm{E}-03)$ & 0.517 \\
\hline & & Protein (1-SD) & $-7.00 \mathrm{E}-05(3.72 \mathrm{E}-03)$ & 0.985 \\
\hline & & Fat (1-SD) & $-8.80 \mathrm{E}-04(3.68 \mathrm{E}-03)$ & 0.811 \\
\hline & & Carbohydrate (1-SD) & $-3.36 \mathrm{E}-03(3.78 \mathrm{E}-03)$ & 0.373 \\
\hline \multirow{12}{*}{ CAVAS } & PRS & Genetic effect $(G)$ & $1.22 \mathrm{E}-02(1.78 \mathrm{E}-03)$ & $8.23 \mathrm{E}-12$ \\
\hline & & Interaction effect (GxE) & & \\
\hline & & Calorie intake (1-SD) & $-9.00 \mathrm{E}-04$ (1.77E-03) & 0.611 \\
\hline & & Protein $(1-S D)$ & $-2.14 \mathrm{E}-03(1.79 \mathrm{E}-03)$ & 0.232 \\
\hline & & Fat (1-SD) & $-2.26 \mathrm{E}-04(1.76 \mathrm{E}-03)$ & 0.898 \\
\hline & & Carbohydrate (1-SD) & $-9.76 \mathrm{E}-04(1.78 \mathrm{E}-03)$ & 0.583 \\
\hline & PRS $_{\text {unweighted }}$ & Genetic effect $(G)$ & 4.00E-02 (4.17E-03) & $1.19 \mathrm{E}-21$ \\
\hline & & Interaction effect (GxE) & & \\
\hline & & Calorie intake (1-SD) & $-3.22 \mathrm{E}-03$ (4.15E-03) & 0.438 \\
\hline & & Protein (1-SD) & $-5.04 \mathrm{E}-03(4.21 \mathrm{E}-03)$ & 0.232 \\
\hline & & Fat (1-SD) & 2.32E-04 (4.14E-03) & 0.955 \\
\hline & & Carbohydrate (1-SD) & $-3.99 \mathrm{E}-03(4.16 \mathrm{E}-03)$ & 0.337 \\
\hline \multirow[t]{12}{*}{ HEXA } & PRS & Genetic effect (G) & $1.25 \mathrm{E}-02(9.72 \mathrm{E}-04)$ & $6.73 \mathrm{E}-38$ \\
\hline & & Interaction effect (GxE) & & \\
\hline & & Calorie intake (1-SD) & $1.31 \mathrm{E}-03$ (9.83E-04) & 0.181 \\
\hline & & Protein (1-SD) & $1.49 \mathrm{E}-03(9.78 \mathrm{E}-04)$ & 0.128 \\
\hline & & Fat (1-SD) & $1.24 \mathrm{E}-03(9.73 \mathrm{E}-04)$ & 0.203 \\
\hline & & Carbohydrate (1-SD) & $1.06 \mathrm{E}-03(9.85 \mathrm{E}-04)$ & 0.280 \\
\hline & $\mathrm{PRS}_{\text {unweighted }}$ & Genetic effect $(G)$ & $3.60 \mathrm{E}-02(2.27 \mathrm{E}-03)$ & $2.87 \mathrm{E}-56$ \\
\hline & & Interaction effect (GxE) & & \\
\hline & & Calorie intake (1-SD) & $-1.74 \mathrm{E}-03(2.31 \mathrm{E}-03)$ & 0.451 \\
\hline & & Protein (1-SD) & $-6.63 \mathrm{E}-04(2.34 \mathrm{E}-03)$ & 0.777 \\
\hline & & Fat (1-SD) & $-3.87 \mathrm{E}-04(2.30 \mathrm{E}-03)$ & 0.867 \\
\hline & & Carbohydrate (1-SD) & $-2.21 \mathrm{E}-03(2.30 \mathrm{E}-03)$ & 0.336 \\
\hline
\end{tabular}

The association between PRS and phenotype and the interaction of PRS with calorie intake were analyzed by linear regression for BMI, and adjusted for age, sex, recruitment area and 10 principal components for KARE, and for sex, age and 10 principal components for CAVAS and HEXA. The significance threshold was $p<4.17 \mathrm{E}-$ 04 (0.05/120 after multiple correction). PRS, polygenic risk score; SE, standard error.

\section{Interaction Analysis between PRS and aPRS with}

\section{Calorie Intake in BMI and Obesity}

We conducted an interaction analysis of the PRS and total calorie intake in the 3 cohorts using linear regression for BMI and logistic regression for obesity. These results indicated that no significant interaction exists between the PRS and total calorie intake for BMI (Table 3) or obesity (online suppl. Table S6). We conducted this analysis also on the intake of protein, fat, and carbohydrates and, again, did not observe any significant interaction with each of these after multiple correction $\left(p<4.17 \times 10^{-4}\right.$; Table 3; online suppl. Table S6). 
Table 4. Association and interaction analyses of aPRS with BMI

\begin{tabular}{|c|c|c|c|c|}
\hline \multirow[t]{2}{*}{ Study } & & \multirow[t]{2}{*}{ Test } & \multicolumn{2}{|l|}{ Obesity } \\
\hline & & & OR (95\% CI) & $p$ value \\
\hline \multirow[t]{12}{*}{ KARE } & aPRS & Genetic effect $(G)$ & $1.97 \mathrm{E}-02(2.79 \mathrm{E}-03)$ & $1.46 \mathrm{E}-12$ \\
\hline & & Interaction effect (GxE) & & \\
\hline & & Calorie intake (1-SD) & 9.64E-04 (2.83E-03) & 0.733 \\
\hline & & Protein (1-SD) & $2.47 \mathrm{E}-03(2.88 \mathrm{E}-03)$ & 0.391 \\
\hline & & Fat $(1-S D)$ & $3.19 \mathrm{E}-03(2.76 \mathrm{E}-03)$ & 0.249 \\
\hline & & Carbohydrate (1-SD) & $-1.03 \mathrm{E}-03(2.85 \mathrm{E}-03)$ & 0.718 \\
\hline & aPRS $_{\text {unweighted }}$ & Genetic effect (G) & 7.59E-02 (6.72E-03) & $2.34 \mathrm{E}-29$ \\
\hline & & Interaction effect (GxE) & & \\
\hline & & Calorie intake (1-SD) & $-5.00 \mathrm{E}-05(6.82 \mathrm{E}-03)$ & 0.994 \\
\hline & & Protein (1-SD) & $3.61 \mathrm{E}-03$ (6.87E-03) & 0.599 \\
\hline & & Fat (1-SD) & $3.95 \mathrm{E}-03(6.81 \mathrm{E}-03)$ & 0.562 \\
\hline & & Carbohydrate (1-SD) & $-4.45 \mathrm{E}-03(6.74 \mathrm{E}-03)$ & 0.510 \\
\hline \multirow[t]{12}{*}{ CAVAS } & aPRS & Genetic effect (G) & $1.92 \mathrm{E}-02(2.72 \mathrm{E}-03)$ & $2.00 \mathrm{E}-12$ \\
\hline & & Interaction effect (GxE) & & \\
\hline & & Calorie intake (1-SD) & $-7.50 \mathrm{E}-05(2.72 \mathrm{E}-03)$ & 0.978 \\
\hline & & Protein (1-SD) & $-1.34 \mathrm{E}-03(2.75 \mathrm{E}-03)$ & 0.625 \\
\hline & & Fat (1-SD) & 6.77E-04 (2.71E-03) & 0.803 \\
\hline & & Carbohydrate (1-SD) & $-5.36 \mathrm{E}-07(2.74 \mathrm{E}-03)$ & 0.9998 \\
\hline & aPRS $_{\text {unweighted }}$ & Genetic effect $(G)$ & $6.91 \mathrm{E}-02(6.43 \mathrm{E}-03)$ & 8.07E-27 \\
\hline & & Interaction effect (GxE) & & \\
\hline & & Calorie intake (1-SD) & $-8.20 \mathrm{E}-04(6.51 \mathrm{E}-03)$ & 0.900 \\
\hline & & Protein (1-SD) & $-2.83 \mathrm{E}-03(6.60 \mathrm{E}-03)$ & 0.668 \\
\hline & & Fat (1-SD) & $2.09 \mathrm{E}-03(6.56 \mathrm{E}-03)$ & 0.750 \\
\hline & & Carbohydrate (1-SD) & $8.69 \mathrm{E}-01(6.52 \mathrm{E}-03)$ & 0.869 \\
\hline \multirow[t]{12}{*}{ HEXA } & aPRS & Genetic effect $(G)$ & $1.85 \mathrm{E}-02(1.65 \mathrm{E}-03)$ & $8.15 \mathrm{E}-29$ \\
\hline & & Interaction effect $(\mathrm{GxE})$ & & \\
\hline & & Calorie intake (1-SD) & $2.07 \mathrm{E}-03(1.64 \mathrm{E}-03)$ & 0.208 \\
\hline & & Protein (1-SD) & $2.01 \mathrm{E}-03(1.63 \mathrm{E}-03)$ & 0.219 \\
\hline & & Fat $(1-S D)$ & $1.60 \mathrm{E}-03(1.63 \mathrm{E}-03)$ & 0.326 \\
\hline & & Carbohydrate (1-SD) & $1.80 \mathrm{E}-03(1.65 \mathrm{E}-03)$ & 0.276 \\
\hline & aPRS $_{\text {unweighted }}$ & Genetic effect $(G)$ & $6.27 \mathrm{E}-02(3.97 \mathrm{E}-03)$ & $5.62 \mathrm{E}-56$ \\
\hline & & Interaction effect (GxE) & & \\
\hline & & Calorie intake (1-SD) & $-1.89 \mathrm{E}-03$ (3.99E-03) & 0.635 \\
\hline & & Protein (1-SD) & $-1.87 \mathrm{E}-04(3.96 \mathrm{E}-03)$ & 0.962 \\
\hline & & Fat (1-SD) & 8.73E-04 (3.94E-03) & 0.824 \\
\hline & & Carbohydrate (1-SD) & $-3.12 \mathrm{E}-03(4.01 \mathrm{E}-03)$ & 0.437 \\
\hline
\end{tabular}

The association between aPRS and phenotype and the interaction of aPRS with calorie intake were analyzed by linear regression for BMI, adjusted for age, sex, recruitment area, and 10 principal components for KARE, and for sex, age and 10 principal components for CAVAS and HEXA. The significance threshold was $p<4.17 \mathrm{E}-04$ (0.05/120 after multiple correction). aPRS, association polygenic risk score; SE, standard error.

Next, we analyzed the interaction of calorie intake and $\mathrm{PRS}_{\text {unweighted }}$ in both BMI and obesity. The results were similar to those fort PRS, in that we did not identify any significant interaction between total calorie, protein, fat, or carbohydrate intake in any of the 3 cohorts (Table 3; online suppl. Table S6).
In addition, we conducted an interaction analysis of the aPRS that was calculated with potentially associated GWAS SNPs in these cohorts. The interactions between aPRS and total calorie intake in all 3 cohorts were performed using linear regression for BMI and logistic regression for obesity. Again, in all 3 cohorts, no interaction 
was observed between aPRS and total calorie intake (Table 4; online suppl. Table S7). Furthermore, when the interactions of protein, fat, and carbohydrate intake were analyzed, there were similar negative results in all 3 cohorts for BMI and obesity (Table 4; online suppl. Table S7).

We also analyzed the interaction of calorie intake with

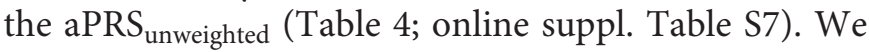
did not observe any significant results for total calorie, protein, fat, or carbohydrate intake in all 3 cohorts.

Recently, a BMI GWAS discovered 941 independent SNPs using around 700,000 participants of European ancestry [15]. We generated another set of BMI PRS using these 941 SNPs $\left(\mathrm{PRS}^{2}\right.$ and $\mathrm{PRS}^{2}$ unweighted and aPRS ${ }^{2}$ and $\mathrm{aPRS}^{2}$ unweighted). Using these, we analyzed the interactions with calorie and macronutrient intakes for BMI, and no significant interactions were observed (online suppl. Tables S8, S9).

\section{Discussion}

In this study, we calculated the PRS on the basis of 347 BMI GWAS SNPs in 35,094 individuals in 3 Korean cohorts, and observed no significant interactions between the PRS and calorie intake for BMI or obesity, in any of the 3 cohorts. In addition, we selected 62 SNPs displaying potential associations with BMI and obesity in the Korean cohorts for the aPRS and, again, observed no interactions in the aPRS for calorie intake based on BMI and obesity in each cohort.

Several methods have been reported for the selection of PRS SNPs in accordance with the appropriate studies to be considered for the interaction: (1) whether all GWAS SNPs, or only ethnically related SNPs were included, (2) whether PRS were determined by being weighted for effect size of SNPs, or unweighted; (3) whether the PRS SNPs were selected by validation in the study samples. We attempted to test for the most likely associations, but no interaction between BMI PRSs and calorie intake were found.

Although previous studies have investigated the interaction between BMI PRS and diverse nutrients including sugar-sweetened beverages, fried foods, carbohydrates, animal protein and fat, and vegetable protein, fat, and fiber [28-31, 40], no study has yet investigated the direct interaction between BMI PRS and total calorie intake. However, Tyrrell et al. [31] analyzed the interactions of PRS with a calorie-dense "Western" diet along with diverse nutrients in the UK Biobank study, and also did not identify any interactions between them based on BMI. This calorie-dense "Western" diet is similar to the total calorie intake in terms of the high consumption of calories.

Interaction Analyses of PRS and Calorie Intake in BMI and Obesity
There are several limitations to this study. The first is the statistical power, which remains a major issue in geneenvironment interaction studies [41-43]. To determine the effects of the interaction between these 2 factors, a sample size 4 times greater than that of the GWAS sample is required [41, 42,44]. We determined the statistical power for this study using the Quanto program. We assumed the following conditions for power calculation: unmatched case-control, 1.5 control per case; risk allele frequency, 0.35; genetic model of log-additive inheritance model, OR for the marginal association between the genetic variant and obesity risk, 1.08; population prevalence for obesity, 42\%; and OR for the marginal association between total calorie intake and obesity risk, 1.05. Approximately 4,000 obesity cases and 5,600 normal controls included here yielded a statistical power of $80 \%$ for the detection of a gene-environment interaction OR of between $1.19(\alpha=0.05)$ and $1.29(\alpha=0.001)$ for common risk alleles (frequency, 35\%). Since there is no evidence to support that the OR for the gene-environment in obesity is as high as 1.19 , the power calculation suggests that a cohort with a much larger sample size is required to detect the interaction for obesity. Therefore, interaction analyses with a much larger sample (at least $>4$-fold greater, at least, is needed to detect an OR $<1.10$ ) are needed for the interaction between PRS and calorie intake to be evident.

This study reports that the PRS conducted with BMI GWAS SNPs are not associated with calorie intake for both BMI and obesity, using data on 35,094 Korean participants from 3 population-based cohorts, and performed with weighted and unweighted PRS and weighted and unweighted aPRS.

\section{Acknowledgements}

This study was conducted with bioresources from the National Biobank of Korea, the Center for Disease Control and Prevention, Republic of Korea (KBN-2019-021, KBN-2020-017). The CAVAS samples were genotyped using the Korea Biobank array (KoreanChip), which was designed and optimized for Korean content by the Center for Genome Science, Korea National Institute of Health, Republic of Korea (4845-301, 3000-3031).

\section{Statement of Ethics}

This study was conducted according to the guidelines established in the Declaration of Helsinki. All participants provided written informed consent to participate in the study. The protocol used for this project was approved by the Institutional Review Board (IRB) of Kyung Hee University (KHSIRB-19-387(EA)). 


\section{Conflict of Interest Statement}

The authors have no conflicts of interest to declare.

\section{Funding Sources}

This work was supported by a grant from Kyung Hee University in 2019 (KHU-20191224) and the National Research Foundation of Korea (NRF) grant funded by the Korea government (MSIT) (the Bio \& Medical Technology Development Program of the NRF (2019M3E5D3073365) and NRF-2018R1D1A1B07049641). The funder had no role in the study design, data collection and analysis, decision to publish, or preparation of the manuscript.

\section{Author Contributions}

W.-J.L. and J.E.L. conceived the original idea for the study, conducted the statistical analyses, and drafted the manuscript. B.O. and J.E.L. provided guidance on study design and statistical analyses. S.Y.R., M.K.K., and Y.-J.K. contributed to the analytical strategy and access to the KoGES consortium data. H.U.J., J.-O.K., T.P, and S.W. provided guidance on statistical analyses. All authors read and approved the final version.

\section{References}

1 Martin KA, Mani MV, Mani A. New targets to treat obesity and the metabolic syndrome. Eur J Pharmacol. 2015 Sep 15;763(Pt A):6474.

2 Fall T, Ingelsson E. Genome-wide association studies of obesity and metabolic syndrome. Mol Cell Endocrinol. 2014 Jan;382(1):74057.

3 Cortese S, Faraone SV, Bernardi S, Wang S, Blanco C. Adult attention-deficit hyperactivity disorder and obesity: epidemiological study. Br J Psychiatry. 2013 Jul;203(1):24-34.

4 Foster GD, Wyatt HR, Hill JO, Makris AP, Rosenbaum DL, Brill C, et al. Weight and metabolic outcomes after 2 years on a lowcarbohydrate versus low-fat diet: a randomized trial. Ann Intern Med. 2010 Aug;153(3): $147-57$.

5 Yoon YS, Oh SW. Sodium density and obesity; the Korea National Health and Nutrition Examination Survey 2007-2010. Eur J Clin Nutr. 2013 Feb;67(2):141-6.

6 Hall KD, Bemis T, Brychta R, Chen KY, Courville A, Crayner EJ, et al. Calorie for Calorie, Dietary Fat Restriction Results in More Body Fat Loss than Carbohydrate Restriction in People with Obesity. Cell Metab. 2015 Sep; 22(3):427-36.

7 Hruby A, Hu FB. The Epidemiology of Obesity: A Big Picture. Pharmacoeconomics. 2015 Jul;33(7):673-89.

8 Laskowski ER. The role of exercise in the treatment of obesity. PM R. 2012 Nov;4(11): $840-4$.

9 Sinha R, Jastreboff AM. Stress as a common risk factor for obesity and addiction. Biol Psychiatry. 2013 May;73(9):827-35.

10 Bayon V, Leger D, Gomez-Merino D, Vecchierini MF, Chennaoui M. Sleep debt and obesity. Ann Med. 2014 Aug;46(5):264-72.

11 Jasik CB. Body image and health: eating disorders and obesity. Prim Care. 2014 Sep; 41(3):519-37.

12 Thorleifsson G, Walters GB, Gudbjartsson DF, Steinthorsdottir V, Sulem P, Helgadottir A, et al. Genome-wide association yields new sequence variants at seven loci that associate with measures of obesity. Nat Genet. 2009 Jan;41(1):18-24.

13 Speliotes EK, Willer CJ, Berndt SI, Monda KL, Thorleifsson G, Jackson AU, et al.; MAGIC; Procardis Consortium. Association analyses of 249,796 individuals reveal 18 new loci associated with body mass index. Nat Genet. 2010 Nov;42(11):937-48.

14 Locke AE, Kahali B, Berndt SI, Justice AE, Pers TH, Day FR, et al.; LifeLines Cohort Study; ADIPOGen Consortium; AGEN-BMI Working Group; CARDIOGRAMplusC4D Consortium; CKDGen Consortium; GLGC; ICBP; MAGIC Investigators; MuTHER Consortium; MIGen Consortium; PAGE Consortium; ReproGen Consortium; GENIE Consortium; International Endogene Consortium. Genetic studies of body mass index yield new insights for obesity biology. Nature. 2015 Feb;518(7538):197-206.

15 Yengo L, Sidorenko J, Kemper KE, Zheng Z, Wood AR, Weedon MN, et al.; GIANT Consortium. Meta-analysis of genome-wide association studies for height and body mass index in 700000 individuals of European ancestry. Hum Mol Genet. 2018 Oct;27(20): 3641-9.

16 Frayling TM, Timpson NJ, Weedon MN, Zeggini E, Freathy RM, Lindgren CM, et al. A common variant in the FTO gene is associated with body mass index and predisposes to childhood and adult obesity. Science. 2007 May;316(5826):889-94.

17 Loos RJ, Lindgren CM, Li S, Wheeler E, Zhao $\mathrm{JH}$, Prokopenko I, et al.; Prostate, Lung, Colorectal, and Ovarian (PLCO) Cancer Screening Trial; KORA; Nurses' Health Study; Diabetes Genetics Initiative; SardiNIA Study; Wellcome Trust Case Control Consortium; FUSION. Common variants near MC4R are associated with fat mass, weight and risk of obesity. Nat Genet. 2008 Jun;40(6): 768-75.

18 Wen W, Zheng W, Okada Y, Takeuchi F, Tabara Y, Hwang JY, et al. Meta-analysis of genome-wide association studies in East Asian-ancestry populations identifies four new loci for body mass index. Hum Mol Genet. 2014 Oct;23(20):5492-504.

19 Akiyama M, Okada Y, Kanai M, Takahashi A, Momozawa Y, Ikeda M, et al. Genome-wide association study identifies 112 new loci for body mass index in the Japanese population. Nat Genet. 2017 Oct;49(10):1458-67.

20 Kilpeläinen TO, Qi L, Brage S, Sharp SJ, Sonestedt E, Demerath E, et al. Physical activity attenuates the influence of FTO variants on obesity risk: a meta-analysis of 218,166 adults and 19,268 children. PLoS Med. 2011 Nov; 8(11):e1001116.

21 Corella D, Ortega-Azorín C, Sorlí JV, Covas MI, Carrasco P, Salas-Salvadó J, et al. Statistical and biological gene-lifestyle interactions of MC4R and FTO with diet and physical activity on obesity: new effects on alcohol consumption. PLoS One. 2012;7(12):e52344.

22 Young AI, Wauthier F, Donnelly P. Multiple novel gene-by-environment interactions modify the effect of FTO variants on body mass index. Nat Commun. 2016 Sep;7(1):12724.

23 Bjørnland T, Langaas M, Grill V, Mostad IL. Assessing gene-environment interaction effects of FTO, MC4R and lifestyle factors on obesity using an extreme phenotype sampling design: results from the HUNT study. PLoS One. 2017 Apr;12(4):e0175071.

24 Langenberg C, Sharp SJ, Franks PW, Scott RA, Deloukas P, Forouhi NG, et al. Gene-lifestyle interaction and type 2 diabetes: the EPIC interact case-cohort study. PLoS Med. 2014 May;11(5):e1001647.

25 Maas P, Barrdahl M, Joshi AD, Auer PL, Gaudet MM, Milne RL, et al. Breast Cancer Risk from Modifiable and Nonmodifiable Risk Factors among White Women in the United States. JAMA Oncol. 2016 Oct;2(10): 1295-302.

26 Redondo MJ, Oram RA, Steck AK. Genetic Risk Scores for Type 1 Diabetes Prediction and Diagnosis. Curr Diab Rep. 2017 Oct; 17(12):129. 
27 Qi Q, Li Y, Chomistek AK, Kang JH, Curhan GC, Pasquale LR, et al. Television watching, leisure time physical activity, and the genetic predisposition in relation to body mass index in women and men. Circulation. 2012 Oct; 126(15):1821-7.

28 Qi Q, Chu AY, Kang JH, Jensen MK, Curhan GC, Pasquale LR, et al. Sugar-sweetened beverages and genetic risk of obesity. $\mathrm{N}$ Engl J Med. 2012 Oct;367(15):1387-96.

29 Qi Q, Chu AY, Kang JH, Huang J, Rose LM, Jensen MK, et al. Fried food consumption, genetic risk, and body mass index: gene-diet interaction analysis in three US cohort studies. BMJ. 2014 Mar;348:g1610.

30 Nakamura S, Narimatsu H, Sato H, Sho R, Otani K, Kawasaki R, et al. Gene-environment interactions in obesity: implication for future applications in preventive medicine. J Hum Genet. 2016 Apr;61(4):317-22.

31 Tyrrell J, Wood AR, Ames RM, Yaghootkar $\mathrm{H}$, Beaumont RN, Jones SE, et al. Gene-obesogenic environment interactions in the UK Biobank study. Int J Epidemiol. 2017 Apr; 46(2):559-75.

32 Cho YS, Go MJ, Kim YJ, Heo JY, Oh JH, Ban $\mathrm{HJ}$, et al. A large-scale genome-wide association study of Asian populations uncovers genetic factors influencing eight quantitative traits. Nat Genet. 2009 May;41(5):527-34
33 Seo MH, Lee WY, Kim SS, Kang JH, Kang JH, Kim KK, et al.; Committee of Clinical Practice Guidelines, Korean Society for the Study of Obesity (KSSO). 2018 Korean Society for the Study of Obesity Guideline for the Management of Obesity in Korea. J Obes Metab Syndr. 2019 Mar;28(1):40-5.

34 Kim MK, Kim K, Shin MH, Shin DH, Lee YH, Chun BY, et al. The relationship of dietary sodium, potassium, fruits, and vegetables intake with blood pressure among Korean adults aged 40 and older. Nutr Res Pract. 2014 Aug; 8(4):453-62.

35 Howie BN, Donnelly P, Marchini J. A flexible and accurate genotype imputation method for the next generation of genome-wide association studies. PLoS Genet. 2009 Jun; 5(6):e1000529.

36 Moon S, Kim YJ, Han S, Hwang MY, Shin DM, Park MY, et al. The Korea Biobank Array: Design and Identification of Coding Variants Associated with Blood Biochemical Traits. Sci Rep. 2019 Feb;9(1):1382.

37 Kim J, Kim Y, Ahn YO, Paik HY, Ahn Y, Tokudome Y, et al. Development of a food frequency questionnaire in Koreans. Asia Pac J Clin Nutr. 2003;12(3):243-50.
38 Ahn Y, Kwon E, Shim JE, Park MK, Joo Y, Kimm K, et al. Validation and reproducibility of food frequency questionnaire for Korean genome epidemiologic study. Eur J Clin Nutr. 2007 Dec;61(12):1435-41.

39 Purcell S, Neale B, Todd-Brown K, Thomas L, Ferreira MA, Bender D, et al. PLINK: a tool set for whole-genome association and population-based linkage analyses. Am J Hum Genet. 2007 Sep;81(3):559-75.

40 Nettleton JA, Follis JL, Ngwa JS, Smith CE, Ahmad S, Tanaka T, et al. Gene $\times$ dietary pattern interactions in obesity: analysis of up to 68317 adults of European ancestry. Hum Mol Genet. 2015 Aug;24(16):4728-38.

41 Hunter DJ. Gene-environment interactions in human diseases. Nat Rev Genet. 2005 Apr; 6(4):287-98.

42 Kraft P, Hunter D. Integrating epidemiology and genetic association: the challenge of geneenvironment interaction. Philos Trans R Soc Lond B Biol Sci. 2005 Aug;360(1460):160916.

43 Simon PH, Sylvestre MP, Tremblay J, Hamet P. Key Considerations and Methods in the Study of Gene-Environment Interactions. Am J Hypertens. 2016 Aug;29(8):891-9.

44 Smith PG, Day NE. The design of case-control studies: the influence of confounding and interaction effects. Int J Epidemiol. 1984 Sep; 13(3):356-65. 